The Laycet,] STRICTURE OF THE GESOPHAGUS.-NAVAL SURGEONS ON HALF-PAY. [APRIL $28,1860$.

heartily wish that 'ere Board of Works, or whatever they call themselves, would help us out with it."

Now, Sir, the idea is this. The large number of river steamers plying between Battersea and London-bridge in summer are constantly stirring up the filth that escapes deodorization in the sewers, wore especially that lying along the banks and barge-stations. The heat of the sun acting on the liquid sewage, increases in an enormous degree the fearful stench. As the steamers cause this, make them consume it, as they do their own smoke. My plan is simply to fit a flat tank on the after-part of the deck, near the steering-wheel, capable of holding about two hogsheads of deodorizing fluid; a pipe descending down the rudder-case would allow the fluid to pass away, regulated by a stop-cock. This would mix efficiently with the sewage stirred up by the paddles, and where the odour was strongest there would the remedy be applied.

Professor Miller acknowledged to me, last summer, that he had no doubt the process would be successful. It is simple, practical, and inexpensive. If half a gallon of Dale's muriate of iron will deodorize 7500 gallons of sewage perfectly, think what may he done by the river steamers in connexion with the deodorization in the sewers. If, Sir, the hint is worthy a place in your columns, give room to this "pleonastic epistle," and oblige your obedient servant,

J. M'Grigor Croft, M.D., M.R.C.P. Lond., Late Staff-Surgeon to $\mathrm{H}$ M $\mathrm{E}$.

Maudarin Villa, Abbey-road, St. John's-wood, April, 1860.

\section{STRICTURE OF THE ESOPHAGUS.}

(LETTER FROM MR. MACILWATN.)

To the Editor of THE LANCET.

Srr,-On almost every occasion on which Strictures of the CEsophagus have been the subject of conversation, I have experienced great difficulty in persuading my surgical brethren that there is much to be done in these cases; whereas, as $I$ have always said, there are no cases in which, if treated with the care necessary, both constitutionally as well as locally, we obtain more gratifying or triumphant issues. I am seldom without a case in illustration of the foregoing assertion. Strictures of the cesophagus are further of creat interest, because in exacting a far more severe or rigid attention to the principles on which these diseases should be treated than is usually given, they bring up in greater relief those which should govern our management of similar affections in other cants of the body.

I have lately received the account of the death of a patient, whose case I published in 1834, and who died only ten days since, at the age of eighty-seven. Her son, from whom $I$ received the narrative, states as follows (the underscoring being his own):-_ I am happy to say, that my dear mother expe. rienced no kind of pain or suffering, and died of no disease. She left this world without a struggle or a groan-a truly happy, peaceful end, quite in character with the Christian life she had lived for eighty-seven years. She did not experience any inconvenience from her swallow, nor require the use of the instrument for the last seven or eight years," \&c.

The case, when I published it, twenty six years ago, was that of a lady, said to have been about fifty years old (though she must, you see, have been nearer sixty). She was a nervous subject, and dated her first difficulty as far back as twenty years. Her treatment consisted of rigid attention to her general health, and the very careful use of a bougie, preceded by three applications of nitrate of silver in solution. Her surgeon in the country-the late Mr. Dyer, of Ringwood-was directed to continue attention to those points on which her general health appeared to depend, and now and then in the course of the year, if anything suggested its propriety, to pass an elastic gum bougie.

As I have already occupied more space than I had hoped to have done, I will only add, that the experience I have had of these cases has convinced me that their imputed obstinacy has resulted (malignant disease apart) from too much reliance having been placed on the local and manipulatory measures, and too little on the constitutional treatment, the success of which is necessary to the efficient and safe progress of the manipulatory proceedings. I am, Sir, your obedient servant,

Albany Court-yard, April, $1860 . \quad$ Geo. Macrlwais, F.R.C.S.

P.S. - The patient resided at a distance in the country, and $I$ only heard of the death the day before the interment, so that there was no opportunity afforded for any examination of the part. - G. M.

\section{NAVAL SURGEONS ON HALF.PAY.} To the Editor of THE LANCET.

Sir,-We beg to enclose you a copy of a requisition presented by a deputation from the medical practitioners of this borough to Sir John Liddell, M.D., Director-General of the Navy.

We are, Sir, yours obediently,

Portsmouth, April, 1860.

$\left.\begin{array}{l}\text { F. J. Burgess, } \\ \text { Fred. Page, }\end{array}\right\}$ Hon. Secs.

"We, the undersigned qualified private practitioners, resident in Portsmouth, Portsea, Southsea, Landport, and Gos. port, beg most respectfully to call the attention of the DirectorGeneral of the Naval Medical Department to the very great injustice we feel we have long been placed under, from the fact of there being young and able naval medical officers settled and practising in this locality, their half-pay placing them in an unfair position as regards ourselves, enabling them to live in a style and dash that generally ensure success. And we further feel ourselves aggrieved, inasmuch as we are called upon largely to contribute towards their support by the present Income-tax, taxing in a serious manner the pockets of our always precarious incomes. We need not state the labour and fatigue attending private compared with official practice; and we now most respectfully solicit that it may please the Director. General to take this representation into his serious consideration, and to relieve us from a grievance which we feel sure has only to be represented to be remedied.

"Frederick Josiah Burgess, Ext. Lic. R. C.P. Lond. \& F.R.C.S. Lond., Hampshire-terrace, Southsea.

Jas. GredthaM, M.R.C.S. Edin., \& L.A.S., King-street, Portsea.

A LLen A. Duxk, M.D., Prince George-street, Portsea.

StePheN R. Niblett, Lic. R.C.P. Edin. \& L.A.S., Daniel-street, Portsea.

Geo. F. Bloxsome, M.R.C.S. \& L.A.S., Brunswickterrace, Southsea.

H. Bloxam, M.R.C.S. \& L.A.S., Parade, Portsmouth. FRED. PAGE, M.D., H.R.C.S., \& L.A.S., Landport.

John O'Sulltvan, L. R. C.P. Lond.

JA Mres Dickson, L. R. C.S. Edin.

G. J. Scale, M.R.C.S. \& L.A.S., Land port, Portsmouth. John Butcher, M. T.C.S. \& L.A.S., Gosport.

John Robert Kealy, M.R.C.S. \& L.A.S., Gosport. WM. JoHN RUNDLE, M.D., Ext. Lic. R.C.P. Lond。 \& M.R.C.S., Gosport.

Henry Slight, M.R. C.S., Highland Cottage.

Julia.y Sligiti, M.R.C.S., Portsmouth.

Gicilard Bachelor, Surgeon, Southsea. "Portsmouth, April 18th, 2860."

\section{COMPLICATED INJURIES ABOUT THE SHOULDER.JOINT.}

To the Editor of THE LANCeT.

SIR,-I beg to make a few remarks on the following paragraph in your impression of April 14th, p. 369 :-

"A case of more than usual interest occurred to me lately in the person of a man, aged sixty, in Abernethy ward, who had sustained an injury to the shoulder three weeks prior to his admission. The head of the humerus was obviously thrown from its socket, and the flattening of the shoulder was unusually great. The deltoid was tight, and the elbow was drawn from the side. The arm was lengthened by one inch. The head of the bone rotated with the shaft; the coracoid process was unbroken, but there was distinct crepitus on moving the arm. The man was very positive in his assurance that the injury was caused by a direct fall on the shoulder. I made an attempt to reduce the dislocation, under chloroform, by the aid of pulleys. I brought the bone towards its natural relation to the acromion process, by extension downwards, with a padded fulcrum in the axilla. The natural rotundity of the shoulder was restored during the extension, but on its remission it dis. appeared. On the second day following, I repeated the attempt, more critically, persevering in the extension for nearly half an hour, but with no better success. While under extension the head of the bone became prominent, but returned to its abnor. mal position on remitting the extending force."

Now, Sir, there is a form of injury of the shoulder commonly recognised by surgical writers, the distinctive characters of which the younger branches of our profession, especially those 